\title{
Functions of the POU domain genes Skn-1a/i and Tst-1/Oct-6/SCIP in epidermal differentiation
}

\author{
Bogi Andersen, ${ }^{1}$ Wendy C. Weinberg, ${ }^{2}$ Oliver Rennekampff, ${ }^{3}$ Robert J. McEvilly, ${ }^{4}$ \\ John R. Bermingham, Jr, ${ }^{4}$ Farideh Hooshmand, ${ }^{4}$ Vyacheslav Vasilyev, ${ }^{4}$ John F. Hansbrough, ${ }^{3}$ \\ Mark R. Pittelkow, ${ }^{5}$ Stuart H. Yuspa, ${ }^{2}$ and Michael G. Rosenfeld ${ }^{4,6}$ \\ ${ }^{1}$ Division of Endocrinology and Metabolism, ${ }^{3}$ Department of Surgery, ${ }^{4}$ Howard Hughes Medical Institute, School and \\ Department of Medicine, University of California, San Diego, La Jolla, California 92037-0648 USA; ${ }^{2}$ Laboratory of Cellular \\ Carcinogenesis and Tumor Promotion, National Institutes of Health (NIH), National Cancer Institute, Bethesda, Maryland \\ 20892 USA; ${ }^{5}$ Departments of Dermatology, and Biochemistry and Molecular Biology, Mayo Clinic, \\ Rochester, Minnesota 55905-0001 USA
}

Here we report on investigation of the role of the POU domain genes Skin-1a/i (Skn-1a/i/Epoc/Oct-11) and Testes-1 (Tst-1/Oct-6/SCIP) in epidermis where proliferating basal keratinocytes withdraw from the cell cycle, migrate suprabasally, and terminally differentiate to form a multilayered, stratified epithelium. The expression of the $S k n-1 a / i$ and Tst-1 genes is linked to keratinocyte differentiation in vivo and in vitro, whereas the ubiquitous POU domain factor Oct-1 is expressed highly in both proliferating and post-mitotic keratinocytes. Analysis of $S k n-1 a / i$ gene-deleted mice reveals that the $S k n-1 a / i$ gene modulates the pattern of expression of the terminal differentiation marker loricrin and inhibits expression of genes encoding markers of the epidermal keratinocyte wounding response. Although epidermis from Tst-1 gene-deleted mice develops normally, epidermis from mice deleted for both $S k n-1 a / i$ and Tst-1 is hyperplastic and fails to suppress expression of K14 and Spr-1 in suprabasal cells when transplanted onto athymic mice. This suggests that Skn-1a/i and Tst-1 serve redundant functions in epidermis. Therefore, at least two POU domain genes, Skn-1a/i and Tst-1, serve both distinct and overlapping functions to regulate differentiation of epidermal keratinocytes during normal development and wound healing.

[Key Words: POU; epidermis; differentiation; wound healing]

Received March 14, 1997; revised version accepted May 23, 1997.

In normal epidermis, homeostasis is maintained precisely by a balance between cell generation in the basal layer and cell death in superficial layers of the skin (Fuchs and Byrne 1994). This strict regulation of cell number, combined with differentiation-specific regulation of expression of several known marker genes, makes the epidermis a particularly suitable organ to study cellular proliferation, differentiation, and the relationship between these two processes (Watt 1989; Fuchs 1993). Based on their protective function, stratified epithelia have evolved intricate regulatory mechanisms involving both cellular proliferation and distinct differentiation pathways to respond to wounding and other injury. The lack of understanding of the molecular mechanisms underlying the formation and maintenance of stratified epithelial tissues, such as epidermis, represents a fundamental problem in biology today.

Adult epidermis is composed of stratified cell layers,

${ }^{6}$ Corresponding author.

E-MAIL boandersen@popmail.ucsd.edu; FAX (619) 534-8180. the innermost being a single layer of basal cells that rests on a basal lamina. Under normal conditions, proliferation of epidermal keratinocytes is restricted largely to a subset of basal cells (Jones et al. 1995). Basal cells are identified by the expression of a pair of keratins, $\mathrm{K} 5$ and K14, which also characterize undifferentiated cells of other stratified epithelia (Dover and Wright 1994). As epidermal keratinocytes migrate from the basal layer to the suprabasal, spinous layers, K5 and K14 expression is repressed, and expression of another keratin pair, $\mathrm{K} 1$ and K10, which identify differentiating keratinocytes is induced. Cells occupying the outer epidermal granular layers express genes whose products are required for aggregation of keratin filaments and formation of the cornified envelope. These proteins, including transglutaminase, filaggrin, loricrin, involucrin, and small proline rich (Spr) proteins, mark terminally differentiating keratinocytes (Fuchs and Byrne 1994).

Tissue-specific POU domain genes encode transcription factors that have important roles in cell determination during organ development (Wegner et al. 1993). The 
POU domain gene designated Skin-1a/i $(S k n-1 a / i$; also referred to as Epoc-1 and Oct-11) is expressed selectively in epidermis and is a candidate for a cell-determining transcription factor in skin (Andersen et al. 1993a; Goldsborough et al. 1993; Yukawa et al. 1993). The Skn-1a/i gene encodes two different factors generated by alternative RNA splicing. One form, Skn-la, is predicted to encode for a $54-\mathrm{kD}$ protein that is known to bind to regulatory sequences and regulate expression of the Kl0 gene (Andersen et al. 1993al, the Spr-2A gene (Fischer et al. 1996), the involucrin gene (Welter et al. 1996), the control regions of human papillomavirus (HPV) 1A (Andersen et al. 1997), and HPV 16, and HPV 18 (Yukawa et al. 1996). The other form, Skn-li, contains a novel motif in the amino terminus that inhibits DNA binding in vitro, and is expressed at low level in normal skin (Andersen et al. 1997).

In addition to $S k n-1 a / i$, the expression of two other POU domain genes has been described in epidermis. One is the ubiquitously expressed Oct-1 (Kambe et al. 1993) that has been implicated in expression of snRNA (Mittal et al. 1996) and histone H2B genes (Das and Herr 1993). The other, Testes-1|Tst-1; also referred to as SCIP and Oct-6), is expressed at high levels in glial and neuronal cells in addition to stratified epithelia, including epidermis (He et al. 1991; Faus et al. 1994). Tst-1 appears to be expressed in suprabasal cells of the epidermis (Faus et al. 1994) and has been shown in transient transfection assays to activate the differentiation specific gene regulatory regions from $\mathrm{K} 10$ and HPV $1 \mathrm{~A}$ (Andersen et al. 1997), and to repress the expression of the basal-type keratins, K5 and K14 (Faus et al. 1994), as well as the involucrin promoter (Welter et al. 1996).

In this paper, we demonstrate that expression of the Skn-1a/i and Tst-1 genes is linked to keratinocyte differentiation, and that disruption of these two genes in mice provides evidence for their redundant function in control of epidermal differentiation.

\section{Results \\ Expression of Skn-1a/i and Tst- 1 is linked to keratinocyte differentiation}

Our initial in situ hybridization studies (Andersen et al. 1993a) indicated that the $S k n-1 a / i$ gene is expressed predominantly in suprabasal cells, but two subsequent reports suggested that its expression may be limited to basal cells (Yukawa et al. 1993; Faus et al. 1994). To resolve this issue, we have localized Skn-la/i and Tst-1 proteins more precisely by immunohistochemistry (Fig. 1A). In neonatal rat skin, Skn-la/i protein localized selectively to epidermal nuclei, with no staining observed in dermal cells (Fig. IA, left panel). Expression was seen in keratinocyte nuclei throughout all layers of the epidermis and in hair follicles, but was highest in post-mitotic, suprabasal cells. Tst-1 clearly exhibited an overlapping pattern of expression with Skn-la/i (Fig. 1A, middle panel), although expression in basal cells was more prominent than Skn-la/i. Expression of both fac- tors overlapped with the suprabasal expression of K10 (Fig. 1A, right panel). In situ hybridization studies demonstrated that, in addition to interfollicular epidermis, $S k n-1 a / i$ and Tst-1 genes were expressed in matrix cells of the hair follicle and in the outer root sheath, respectively (Fig. 1B). From these results, we conclude that, in contrast with the distribution of specific cytokeratins, expression of $S k n-1 a / i$ and Tst- 1 is not strictly compartmentalized to basal or suprabasal cells. However, expression of both factors is highest in suprabasal cells of the interfollicular epidermis, and clearly overlaps with specific markers of differentiating epidermal keratinocytes.

Primary cultures of epidermal keratinocytes provide a useful system to evaluate regulation of $\mathrm{Skn}-\mathrm{la}$ and other octamer DNA-binding activities during the differentiation process. When human epidermal keratinocytes cultured in serum-free medium are sub-confluent, they proliferate and generally do not express molecular markers of terminal differentiation. On confluence, cells growtharrest and initiate expression of $\mathrm{K} 1$ and $\mathrm{K} 10$, indicative of commitment to differentiation similar to epidermal keratinocyte differentiation from the basal layer (Poumay and Pittelkow 1995). To begin to define potential roles for POU domain factors in epidermal development, the activity of octamer-binding proteins was examined by isolating nuclear extracts from human keratinocyte cultures under three different conditions-proliferating subconfluent (undifferentiated), 12-24 hr after confluence, and $48 \mathrm{hr}$ after confluence. In nonconfluent cultures, two major octamer-binding activities, referred to as complex I and II, were observed (Fig. 1C). The slower migrating complex I proved to be the ubiquitous POU domain factor Oct-1 (Fig. 1E). Surprisingly, the faster migrating complex II appeared to have a different mobility than that of the Skn-la/Tst-1 complex found in mouse skin extracts (Andersen et al. 1997). In the cultures harvested $12-24 \mathrm{hr}$ after confluence, complex II decreased in intensity and a faster migrating complex, complex III, which migrated similar to the Skn-la/Tst-1 complex in mouse skin extracts, became visible (Fig. 1C). In the cultures harvested $48 \mathrm{hr}$ after confluence, complex II had disappeared and complex III was much more intense (Fig. 1C). Formation of both complex I and complex II proved to be dependent on an intact octamer site (Fig. 1D; lane 2) and was insensitive to changes in the heptamer part of the oligonucleotide site (Fig. 1D; lane 1). Similar results were observed for complex III (data not shown). Therefore, all three complexes contain authentic octamer-binding proteins. Taken together, these experiments indicate that although Oct-1-binding activity remains unchanged, keratinocyte differentiation correlates with reciprocal upand down-regulation of two additional octamer-binding activities.

To identify the proteins responsible for octamer-binding activities I-III, antibody perturbation of the gel mobility shift assay was used. Oct-1 antisera selectively disrupted complex I both in undifferentiated and differentiated nuclear extracts (Fig. 1E; lanes 2 and 7). Surprisingly, Oct-2 antisera selectively disrupted complex II in the undifferentiated keratinocytes (Fig. 1E; lane 3). Al- 
A
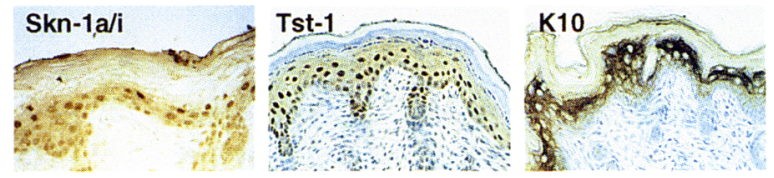

B
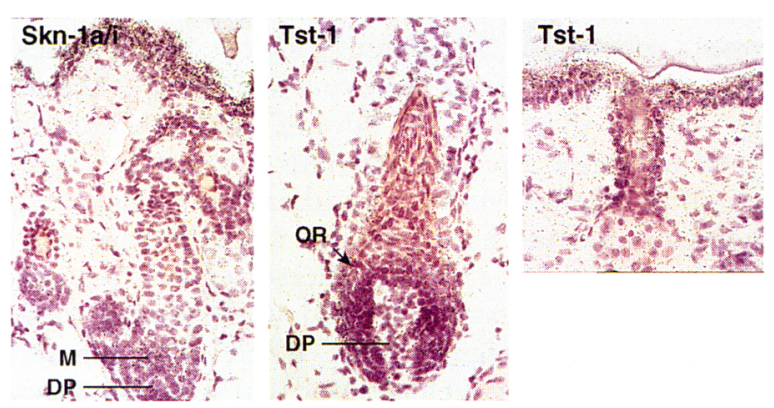

C
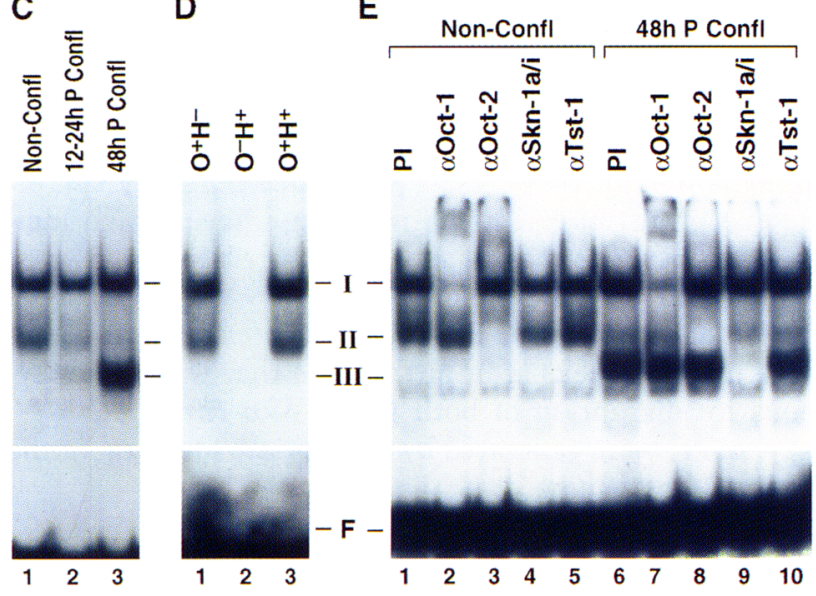

Figure 1. Differentiation-dependent expression of $S \mathrm{kn}-1 \mathrm{a} / \mathrm{i}$ and Tst-1. (A) Immunolocalization of Skn-1a/i, Tst-1, and K10 proteins in epidermis. Antisera specific for Skn-1a/i (left panel), Tst-1 (middle panel), and K10 (right panel) were incubated with fixed paraffin-embedded sections from neonatal rat skin and signal was detected with peroxidase staining. Sections were either not counterstained (Skn-1a/i) or stained with hematoxylin (Tst-1 and K10). Comparison with sections incubated with preimmune sera indicated that $S \mathrm{kn}-1 \mathrm{a} / \mathrm{i}$ and Tst-1 proteins are expressed at low level in basal cells and much higher in suprabasal cells (data not shown). (B) In situ localization of transcripts for Skn-1a/i and Tst-1 in interfollicular epidermis and hair follicles. Light-field photographs from fixed and paraffin-embedded mouse skin sections that were hybridized with cRNA probes specific for Skn-1a/i (left panel), and Tst-1 (middle and right panels). (DP) Dermal papilla, (M) matrix cells; (OR) outer root sheath cells. $(C)$ Alteration in octamer DNA-binding activity during differentiation of human epidermal keratinocytes in vitro. Human epidermal keratinocytes were isolated under three different conditions: nonconfluent (undifferentiated; lane 1), 12-24 hr after confluence (differentiating; lane 2) and $48 \mathrm{hr}$ after confluence (differentiated; lane 3). Nuclear extracts were prepared and incubated with a ${ }^{32} \mathrm{P}$-labeled octamer site in the gel mobility shift assay. I, II, and III refers to the location of three distinct bound octamer complexes. (F) Free probe. $(D)$ Nuclear extracts were prepared from undifferentiated epidermal keratinocytes and incubated with the following ${ }^{32} \mathrm{P}$-labeled DNA sites: $\mathrm{O}+\mathrm{H}-($ lane 1$) ; \mathrm{O}-\mathrm{H}+($ lane 2) and $\mathrm{O}+\mathrm{H}+($ lane 3) in the gel mobility shift assay. $(E)$ Nuclear extracts from undifferentiated (lanes 1-5) and differentiated (lanes 6-10) epidermal keratinocytes were incubated with the $\mathrm{O}+\mathrm{H}-$ site in the gel mobility shift assay. The indicated pre-immune (PI) or antisera $(\alpha)$ were incubated in the binding reactions. though Oct-2 has a wider expression pattern than originally thought, this is the first evidence of Oct-2 in epidermal keratinocytes. Complex III was decreased dramatically with preincubation with Skn-la/i antisera (Fig. 1E; lane 9), but only decreased slightly by preincubation with Tst-1 antisera (Fig. 1E; lane 10). In other experiments, preincubation with Tst- 1 antisera has resulted in a more significant change in this complex (Andersen et al. 1997). These results demonstrate that the major octamer-binding activities in undifferentiated keratinocytes are Oct-1 and Oct-2, whereas in differentiated keratinocytes, Oct-1, Skn-la, and Tst-1 represent the major octamer-binding activities. The induction of Skn-1a and Tst-1 DNA-binding activity is regulated at a pre-translational level as assessed by Western blotting with specific antisera to these factors (data not shown). Collectively, these experiments are consistent with a function for Skn-1a and Tst-1 in terminal differentiation of epidermal keratinocytes.

\section{Promotion of epidermal keratinocyte differentiation by Skn-1a}

The availability of the in-vitro differentiation model provided us with an experimental system to test potential effects of Skn-la on differentiation. For this purpose, the Skn-1a cDNA under control of the cytomegalovirus (CMV) enhancer/promoter was inserted into a replication-deficient adenovirus (Graham and Prevec 1992). To test for expression, viral isolates were used to infect CV-1 cells, and $24 \mathrm{hr}$ later these cells were analyzed with immunostaining by Skn-1a/i antisera. The virus infected efficiently all or a large portion of cells in contrast to transfection of a CMV expression plasmid, where expression was only found in a limited subset of cells (Fig. 2A; data not shown). From these experiments, we conclude that the adenovirus efficiently expressed the Skn-1a protein. To demonstrate that the Skn-la virus could infect and produce functional Skn-1a protein in epidermal keratinocytes, we infected proliferating epidermal keratinocyte cultures with increasing levels of viral stock. Subsequently, nuclear extracts were isolated and DNAbinding tested in the gel mobility shift assay. We observed a dose-dependent formation of a Skn-la-octamer complex (Fig. 2B), indicating that epidermal keratinocytes were infected efficiently and that the Skn-la protein expressed from the adenovirus was capable of binding to cognate DNA sites.

To test the effect of Skn-la on keratinocyte differentiation, proliferating keratinocytes were infected with the Skn-la adenovirus. Infection with Skn-la virus alone had no specific effect on expression of the commitmentto-differentiation marker K10, and proliferation continued in keratinocytes expressing Skn-la (data not shown). Because terminal differentiation of epidermal keratinocytes in vitro can be promoted by activation of protein kinase C (Dlugosz and Yuspa 1993; Rutberg et al. 1996; Stanwell et al. 1996), we tested whether a Skn-la effect could be observed when cells were treated simultaneously with phorbol ester. When proliferating cultures were treated simultaneously with phorbol ester and infected with the Skn-la adenovirus, they arrested growth 
A

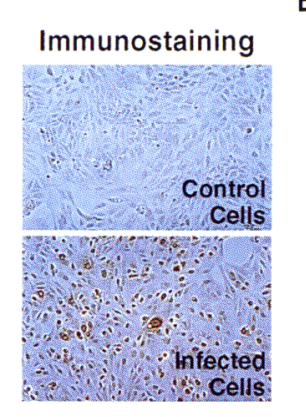

C

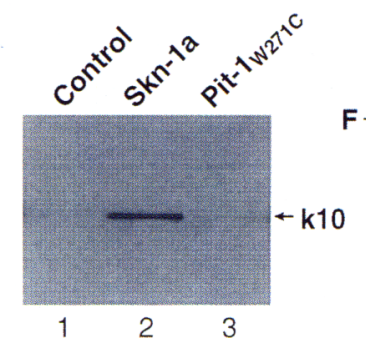

Figure 2. Induction of endogenous $\mathrm{K} 10$ expression by adenovirally expressed Skn-la. (A) Skn-1a/i immunostaining of CV-1 cells that were infected with a control virus (upper panel) or infected with Skn-1a adenovirus (lower panel). (B) Proliferating epidermal keratinocytes were mock-infected (lane 1) or infected with decreasing amounts of Skn-la adenovirus (lanes 2-5) or Pit- 1 adenovirus containing a W271C mutation (P; lane 6). Nuclear extracts were isolated and analyzed in the gel mobility shift assay with a ${ }^{32} \mathrm{P}-$ labeled $\mathrm{O}+\mathrm{H}-$ site. Location of Oct-1 (I), Oct-2 (II), and Skn-1a (III) complexes is indicated. (F) Free probe. (C) Proliferating epidermal keratinocytes were mock-infected (lane 1), infected with Skn-la adenovirus (lane 2) and adenovirus expressing a mutated Pit-1 factor (lane 3). Cytoplasmic extracts were separated by SDS-polyacrylamide electrophoreses and transferred to nitrocellulose followed by immunodetection with a K10 antibody.

and expressed $\mathrm{K} 10$ (Fig. 2C, lanes 1 and 2). The induction of $\mathrm{K} 10$ expression was dependent on the Skn-la protein, because although phorbol ester alone caused growth arrest, it inhibited the low basal level expression of K10 in proliferating keratinocytes, and because phorbol ester treatment in combination with adenovirus expression of a non-DNA-binding form of the POU domain protein Pit-1 had no effect on K10 expression (Fig. 2C, lane 3). Under culture conditions near confluence, phorbol ester inhibited K10 expression, consistent with results obtained with cultured mouse keratinocytes (Dlugosz and Yuspa 1993|, but expression of Skn-la prevented this inhibition (data not shown). These experiments provide evidence that Skn-la can exert a role in differentiation of epidermal keratinocytes and are consistent with in vitro data suggesting that the K10 promoter could be a natural target of Skn-1a (Andersen et al. 1993a).

\section{Generation of Skn-1a/i (-/-) and Skn-1a/i:Tst-1 double mutant mice}

To begin to test the role of the $S k n-1 a / i$ gene in the context of a whole animal, we disrupted the gene in em- bryonic stem (ES) cells using homologous recombination with positive/negative selection (Thomas and Capecchi 1987). Several $S k n-1$ a/i genomic clones were isolated from a mouse 129 /Sv genomic library, and a knockout vector was designed to remove a large part of the $S k n-1$ $a / i$-coding region (Fig. 3A). Four of 200 ES cell lines analyzed exhibited the characteristic restriction fragment length polymorphism on a Southern blot suggesting homologous recombination of the target vector into the Skn-1 a/i locus (Fig. 3B,C). Microinjection of these ES cell clones into blastocysts and implantation into the uterus of pseudopregnant mice, followed by appropriate breeding ultimately yielded mice that were homozygous $(-/-)$ for the $S k n-1 a / i$ mutation. The absence of the deleted coding sequence was confirmed by PCR (Fig. 3D; lanes 2 and 7). Generation of Tst-1 (-/ - mice, in which sequences encoding the amino terminus and POU domain were removed, has been reported previously (Bermingham et al. 1996). Tst-1 (-/-) mice generally exhibit a delay in peripheral myelination and have a high incidence of perinatal death, apparently attributable to a respiratory defect (Bermingham et al. 1996; Jaegle et al. 1996), but a subset of these gene-deleted mice can survive up to 3 weeks after birth. Mice that were homozygous for disruption of both genes, Skn-1a/i:Tst-1 (-/-: $-/-\mid$ mice, were generated by appropriate breeding of the two mutant strains.

\section{Modification of loricrin expression in Skn-1a/i (-/-) mice and delayed postnatal epidermal development in Tst-1 (-/-) mice}

Skn-1a/i gene-deleted mice appeared to have a normal life span, their skin and fur appeared grossly normal, and microscopic examination of hematoxylin/eosin stained skin from $S k n-1 a / i|-|-\mid$ mice, both from neonates and adults, also revealed no apparent structural abnormality (Fig. 4). Because of the respiratory defect in Tst-1 $(-/-)$ mice, only neonates could be examined, but similar to the $S k n-1 a / i(-/-)$ mice, there was no overt histological abnormality in the Tst-1 (-/-) or Skn-1a/i:Tst-1 (-/-:-/-) mice (Fig. 4). To assess whether epidermal differentiation was altered by these mutations, we immunostained skin with antisera specific for K1, K14, loricrin, and filaggrin. These studies demonstrated consistent changes in loricrin expression in neonatal and adult $S k n-1 a / i(-/-)$ mice; positive cells were more superficial and the layer of loricrin positive cells appeared thinner and less intense (Fig. 5A). Skn-1a/i (+/-) mice were indistinguishable from wild-type mice (data not shown). Loricrin expression was normal in neonatal Tst-1 $(-/-)$ mice and there was no accentuated abnormality of loricrin expression in the Skn-1a/i:Tst-1 $(-/-:-/-)$ mice (data not shown). Expression of K1, K10, K14, and filaggrin, as assessed by immunostaining, was normal in all three genotypes examined (data not shown).

Transcript expression for markers of epidermal differentiation was determined in all three genotypes at different stages after birth by Northern blotting (Fig. 5B) or RNase protection assays (Fig. $5 \mathrm{C}$ ). No major alterations 

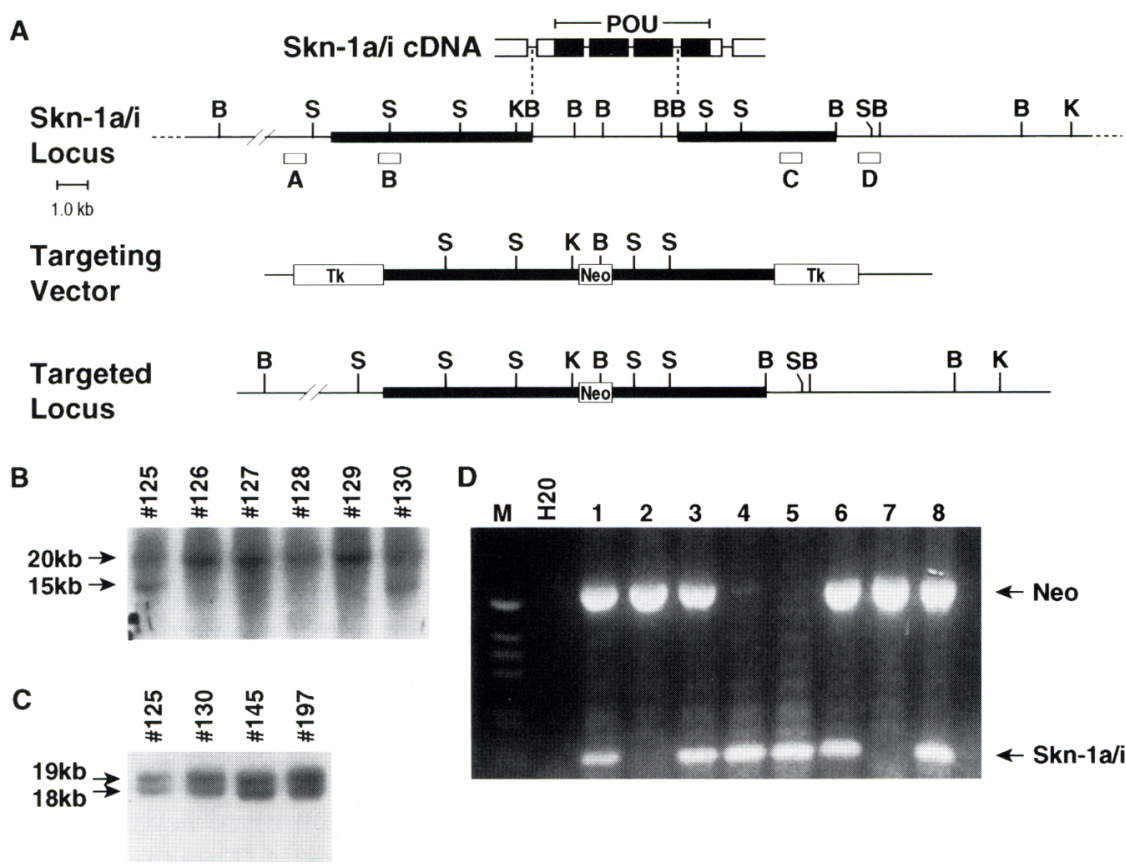

Figure 3. Targeting vector, and strategy for $S k n-1 a / i$ gene deletion. (A) The top panel shows the exon-intron structure around the POU domain of the $S k n-1 a / i$ gene. Coding regions and introns are indicated with boxes and thin lines, respectively. The black boxes represent the POU domain. The upper middle panel is a restriction map of the $S k n-1 a / i$ locus with the two arms (7.0- and 5.5-kb long) used for the targeting vector shown as thick lines. The positions of probes used to identify homologous recombinants are indicated with the small open boxes labeled A-D. The lower middle panel shows the design of the targeting vector. The bottom panel shows the predicted recombined locus where the neomycin gene has replaced $5.0 \mathrm{~kb}$ of the $S k n-1 a / i$ gene, which includes part of the amino-terminus, all the POU-specific domain and a large part of the POU homeodomain. (B) BamH1; (K) Kpn1; (S) Sac1. (B) A Southern blot showing Kpn1-cut DNA from recombined ES cell lines 125-130. The probe used was $D$, which is expected to give a band of $25 \mathrm{~kb}$ in wild-type and $15 \mathrm{~kb}$ in homologous recombined locus. (C) A Southern blot showing BamH1-cut DNA from several recombined ES cell lines probed with probe $\mathrm{B}$, which is expected to give a band of 18 and $19 \mathrm{~kb}$ in wild-type and recombined loci, respectively. $(D)$ Analyses by PCR of genomic DNA from offspring of a cross between two mice that were heterozygous for the $S k n-1 a / i$ locus. Oligonucleotides specific for the neomycin gene (Neo) and a deleted part of the $S k n-1 a / i$ POU domain were used (Skn-1a/i). $\left(\mathrm{H}_{2} \mathrm{O}\right)$ Water control with no DNA; (M) DNA size markers.

were observed in the expression of $\mathrm{K} 1, \mathrm{~K} 10$, loricrin, or $\mathrm{K} 14$ in neonatal or adult $S k n-1 a / i(-/-)$ mice, neonatal Tst-1 (-/-) mice, or neonatal Skn-1a/i:Tst-1 (-/-:-/-) mice (Fig. 5B; data not shown). Expression of the differentiation markers $\mathrm{Kl}$ and loricrin decreased during the first weeks of postnatal life in the mouse, a change that

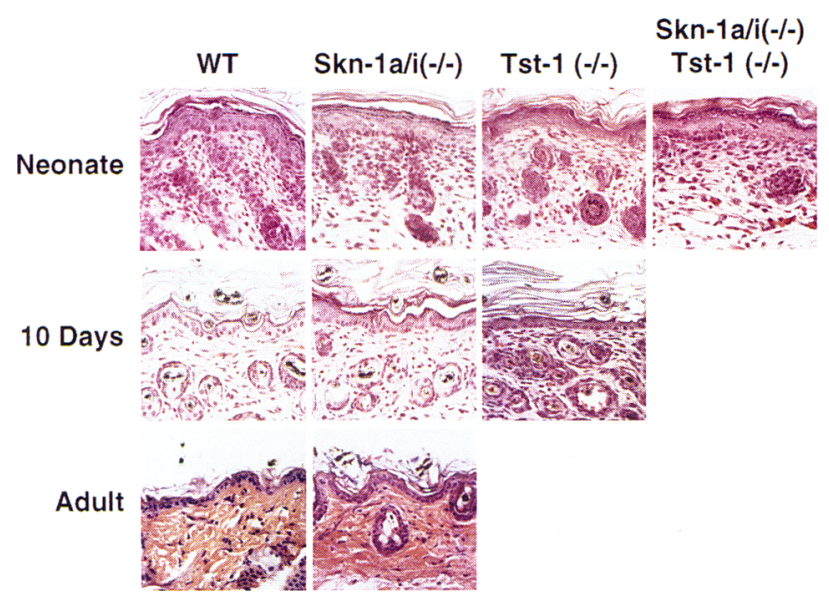

Figure 4. Histology of skin from POU domain gene-deleted mice. Skin was isolated from mice of the indicated genotypes at birth (top panel), at day 10 (middle panel), and from adult mice (bottom panel). Tissue was fixed in formalin, embedded in paraffin, cut into $5-8-\mu \mathrm{m}$ sections, stained with hematoxylin and eosin, and photgraphed by light microscopy. correlated with the thinning of the epidermis during the same time period in rodents (Miadelets 1995). Although a similar pattern was observed in the $S k n-1 a / i(-\mid-)$ mouse, expression of $\mathrm{K} 1$ and loricrin transcripts (Fig. 5B) and proteins (data not shown) was maintained at high level in the viable Tst-1 $(-\mid-)$ mice that lived to 2 weeks. In neonatal Tst-1 $(-/-)$ mice there was no change in $S k n$ $1 a / i$ expression, whereas in the surviving Tst-1 $|-|-\mid$ outliers, Skn-1a/i expression was accentuated, consistent with higher expression levels of the differentiation markers $\mathrm{K} 1$ and loricrin in these mice. Oct- 1 expression was constant in all three genotypes (Fig. $5 \mathrm{C}$ ) and there was no evidence for up-regulation of Tst-1 gene expression in the $S k n-1 a / i(-/-)$ mice (data not shown).

\section{Redundant functions for Skn-1a/i and Tst-1 genes in epidermis}

Because most Tst-1 $(-/-)$ mice die soon after birth, it became difficult to examine the effect of this gene on epidermal function and hair development in older animals. To circumvent this limitation, we transplanted neonatal skin to athymic mice to permit study of postnatal skin development and function (Black and Jederberg 1985), by comparing transplanted skin from Skn$1 a / i$ or Tst-1 gene-deleted mice with that of mice in which both genes have been deleted.

Three weeks after transplantation the $S k n-1 a / i$ Tst-1 (-/-:-/-) skin showed prominent flakiness and less hair growth compared with skin transplanted from single 
A

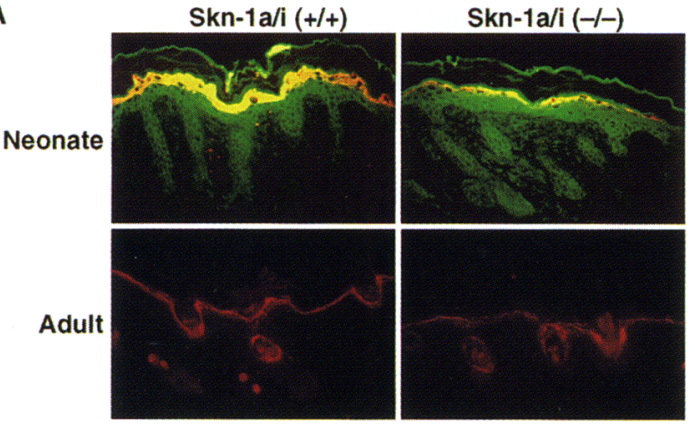

B

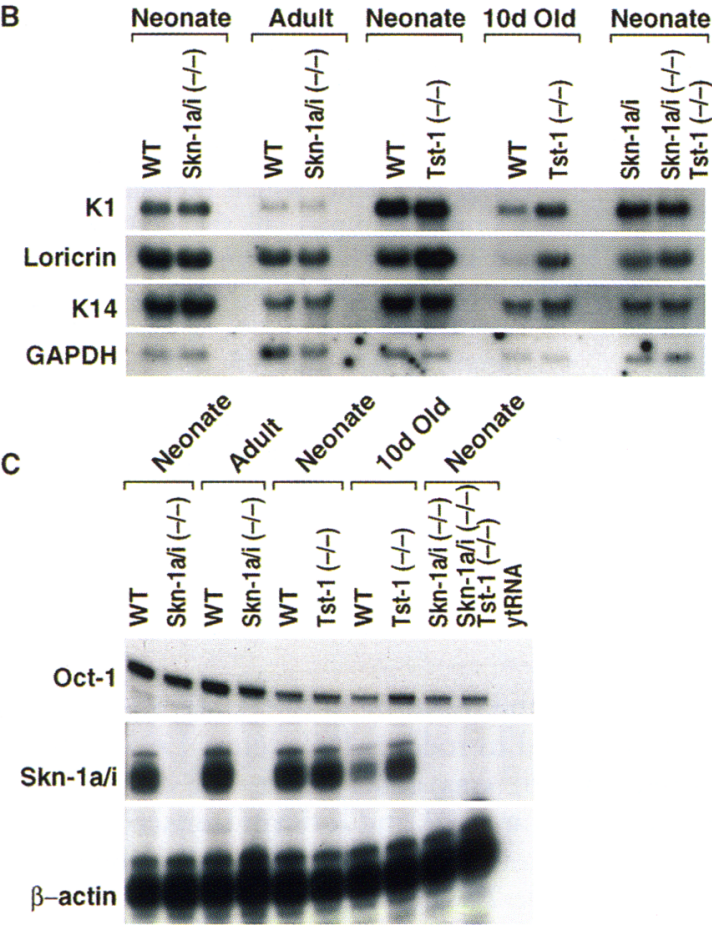

Figure 5. Expression of epidermal differentiation markers in POU domain gene-deleted mice. $(A)$ Back skins from wild-type (left panel) and $S k n-1 a / i(-/-)$ mice were fixed in $70 \%$ ethanol, paraffin-embedded, sectioned, and stained with antisera specific for K14 and loricrin (top panel) or loricrin alone (bottom panel), followed by immunofluorescence microscopy. (B) Total RNA was isolated from the back skin of mice of the indicated age and genotypes. RNA was size fractionated by denaturing gel electrophoresis and transferred to an immobilizing membrane. These Northern blots were subsequently hybridized to the indicated probes. The results presented are representative of two to four different experiments. (C) Total RNA was isolated as described above and expression of the indicated transcripts was analyzed by RNase protection assays. Genotypes and age of mice are indicated above.

gene-deleted and wild-type mice (Fig. 6; data not shown). The general appearance of the Skn-1a/i:Tst-1 double knockout skin improved with time, including hair growth (Fig. 6; data not shown). Skin grafts were examined histologically, and by in situ hybridization with probes for differentiation markers after 6-8 weeks. The presence of the $1 a c Z$ gene in all mice containing trans- planted skin with the Tst-1 mutation allowed us to locate precisely the junction of the transplanted skin in these mice (Fig. 6) and in other mice-the pattern of hair growth allowed the demarcation of the transplanted skin. Histological examination at 6 weeks demonstrated consistently that Skn-1a/i:Tst-1 double knockout epidermis was thicker, containing more cell layers, than epidermis from wild-type, $S k n-1 a / i$-, or Tst-1- deleted mice (Fig. 7). Although the pattern of mRNA expression for $\mathrm{K} 1$, loricrin, and filaggrin was similar in all four genotypes, a striking finding was that expression of K14 extended into the suprabasal cells of epidermis in most sections of skin grafts derived from double knockout skins (Fig. 7). In addition, interfollicular expression of Spr-1 was prominent in the transplanted skin from double knockout mice (Fig. 7). Finally, immunostaining showed that involucrin protein expression extended further toward the basal cell layer in the double knockout mice (data not shown). Collectively, these findings indicate that simultaneous mutation of the $S k n-1 a / i$ and Tst-1 genes leads to epidermal hyperplasia, failure to suppress expression of K14, and abnormal activation of expression of Spr-1 in suprabasal cells. Therefore, these studies have revealed a phenotype in the double knockout skin that is not observed in skin from animals harboring single gene deletions. Taken together, these findings suggest that, whereas deletion of the $S k n-1 a / i$ gene alone has little effect, it collaborates with the Tst-1 gene to regulate differentiation/proliferation in epidermis, therefore explaining the more severe phenotype of the double knockout mice.

\section{Epidermal keratinocytes in Skn-1a/i (-/-) mice are "hyperactive" during wound healing}

We examined the function of the Skn-1a/i gene in wound healing by transplanting autologous meshed skin (Cooper et al. 1991; Hansbrough et al. 1992). Wound healing in $S k n-1 a / i(-/-)$ mice was compared with control mice on day 7 and day 21 after wounding. During healing, epidermal keratinocytes migrate to close the defect, and proliferation of basal cells adjacent to the wound edge is increased (Stenn and Malhotra 1992). Early in wound healing, when active epidermal cell migration was observed, $S k n-1 a / i$ expression was repressed in the migrating epithelial cell front (Fig. 8A, left panel). These wound margin keratinocytes were post-mitotic, similar to suprabasal cells, as demonstrated by proliferating cell nuclear antigen (PCNA) staining (Fig. 8A, right panel). However, they exhibited a number of features that were distinct from normal, unwounded suprabasal cells, including repression of expression of $\mathrm{K} 1$, loricrin, and filaggrin, as well as activation of $\mathrm{K} 14$ and Spr-1 (Fig. $8 \mathrm{~B}$, left panels; data not shown). Macroscopic and histological analysis of wound epithelialization in the $S \mathrm{kn}$ $1 a / i(-/-)$ mice indicated that at day $7,54 \%$ of graft interstices were closed compared with $17 \%$ in controls, indicating a tendency for faster epithelialization in the Skn-1a/i (-/-) mice. Analysis of the wounds by in situ hybridization demonstrated that both K14 and Spr-1 


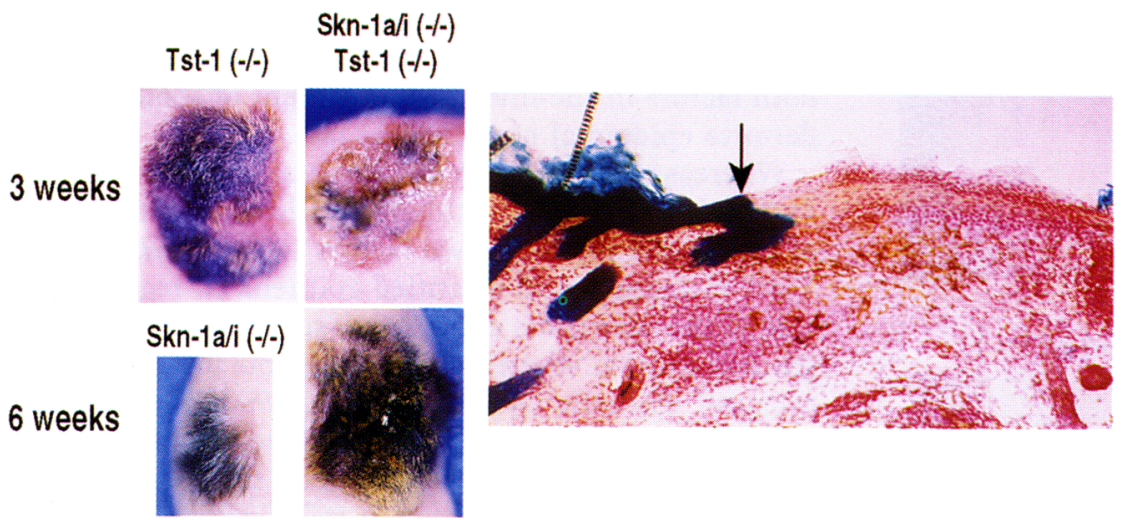

Figure 6. Transplant of neonatal mouse skin to athymic mice. The left panels show the general appearance of skin transplants of the indicated genotypes after the indicated time periods. The right panel shows a light photomicrograph of transplanted skin after staining for $\beta$ galactosidase activity. The arrow indicates the junction between transplanted and host skin. were expressed at higher level in knockout animals compared with controls, whereas repression of K1 and loricrin appeared similar in both groups. Similar results were obtained for incisional wounds examined by Northern blot analysis (Fig. 9A). There was no difference in epithelialization or marker expression between the experimental groups at day 21 after wounding. Consistent with our findings in wound healing, Skn-1a/i $|-|-\mid$ mice also exhibited higher Spr-1 expression after acute treament of skin with phorbol ester (Fig. 9B). These results are consistent with a model predicting that $S k n-1 a / i$ promotes normal differentiation of epidermal keratinocytes and inhibits the phenotypic expression of wound front kera- tinocytes. With the deletion of the $S k n-1 a / i$ gene, this phenotype is exaggerated (Fig. 9C).

\section{Discussion}

Octamer-binding proteins during epidermal differentiation

Our results indicate clearly that both $S k n-1 a / i$ and $T s t-1$ exert functions associated with differentiation of epidermal keratinocytes. Our conclusion is supported by the fact that both transcripts and proteins are found predominantly in suprabasal cells in neonatal epidermis, and that both are expressed at very low levels in prolif-

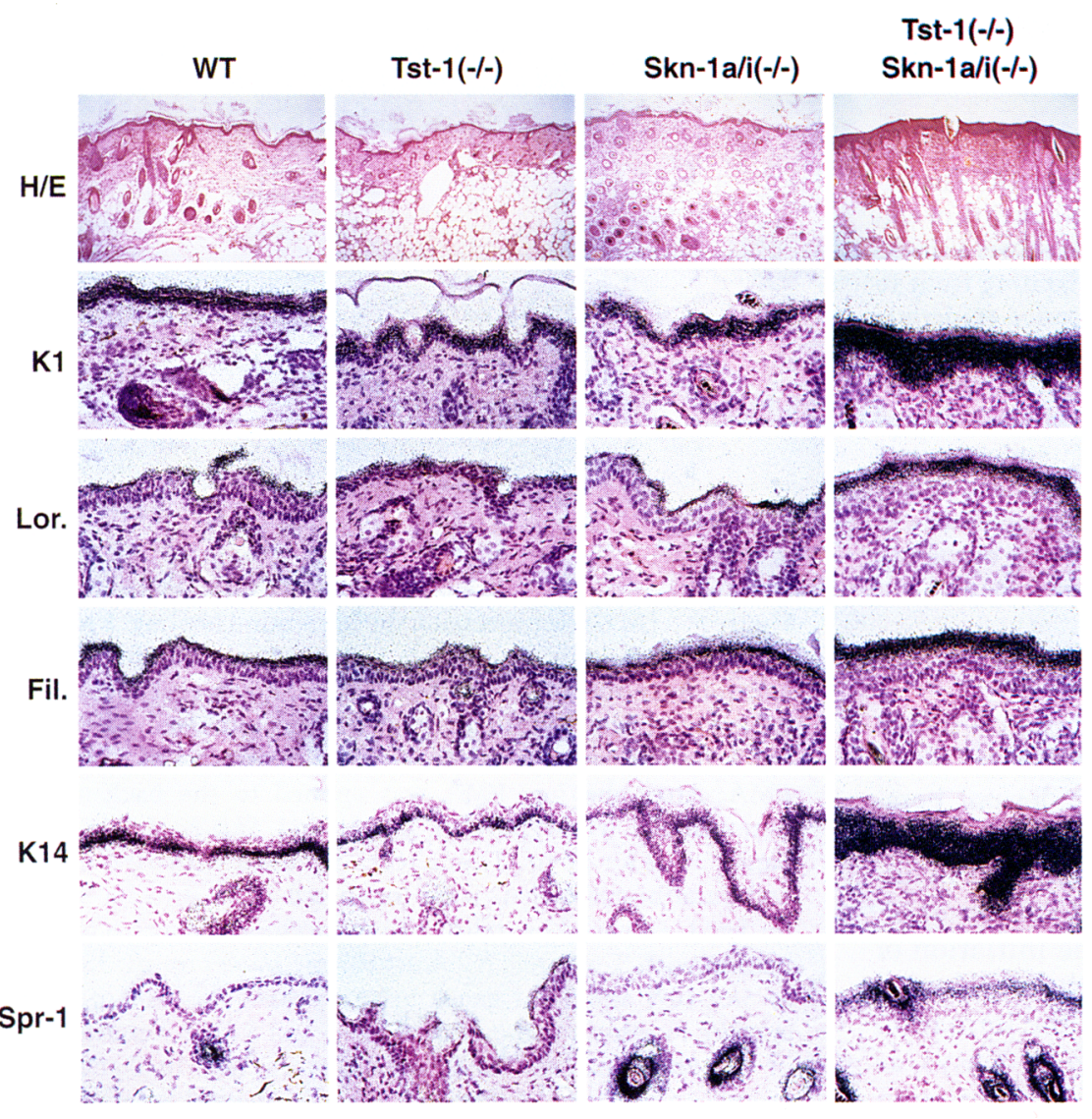

Figure 7. Histology and gene expression in transplanted epidermis. Skin was isolated from transplanted athymic mice, fixed in formalin, and paraffin-embedded. The top panel shows the hematoxylin/eo$\sin (\mathrm{H} / \mathrm{E})$ stained sections $(100 \times$ magnification). Other panels show light-field microscopy results after in situ hybridization with the indicated probes $(400 \mathrm{X}$ magnification). The genotypes are indicated at top. 
A
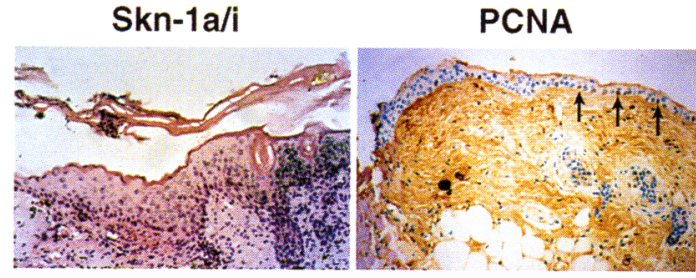

B

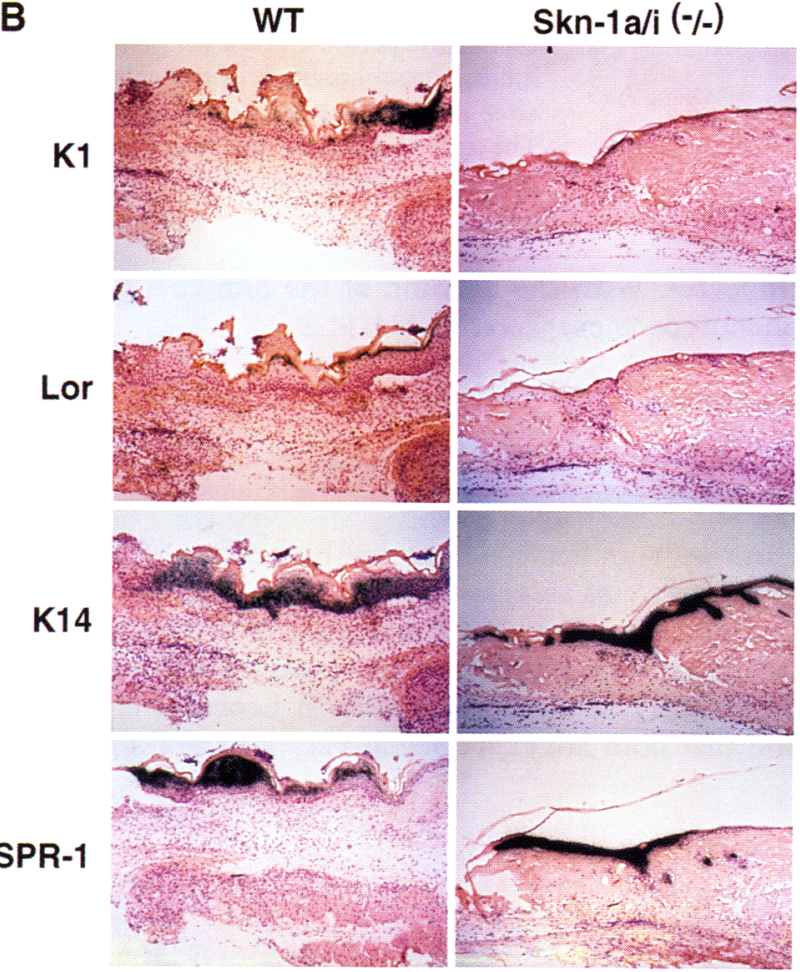

genes $\mathrm{K} 1$ by $\leqslant 1$ day, loricrin by 1 day, and filaggrin by 3 days. This expression pattern is consistent with a role for both factors in the initial commitment of somatic ectoderm to epidermal keratinocyte fate.

Whereas the overlap in the expression pattern of Skn$1 \mathrm{a} / \mathrm{i}$ and Tst- $\mathrm{l}$ is striking, there are also distinct domains of expression for these two factors in epithelial tissues. Tst-l is expressed in stratified epithelia in regions outside of the skin (Faus et al. 1994), such as in the esophagus and mouth, whereas $\mathrm{Skn}-1 \mathrm{a} / \mathrm{i}$ seems to be absent in mucosal epithelia (Andersen et al. 1993a). In hair follicles, Tst-1 is expressed most prominently in the outer root sheath, whereas $S k n-1 \mathrm{a} / \mathrm{i}$ appears to be most prominent in matrix cells of the hair follicle (Fig. 2B). Given

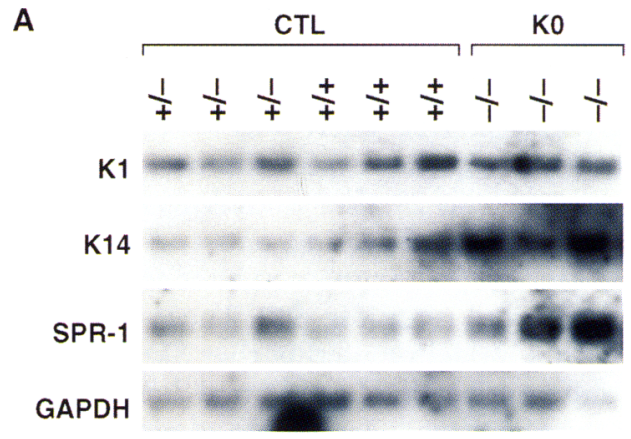

B

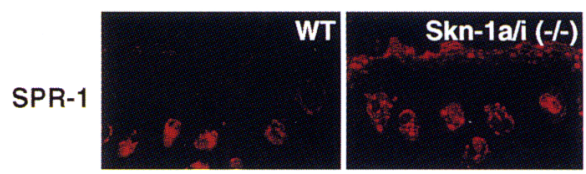

C

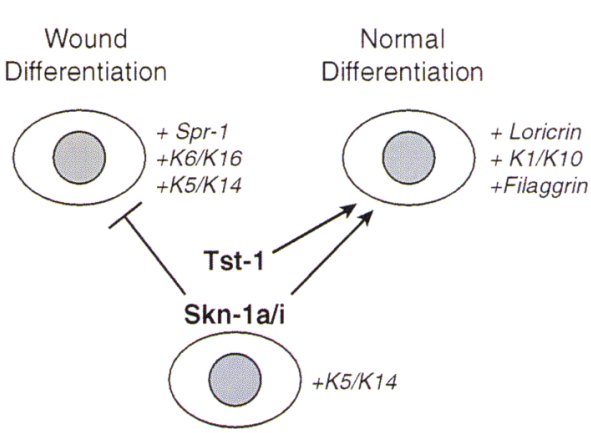

Figure 9. $(A \mid$ Gene expression during wound healing. RNA was isolated from incision wounds 5 days after wounding from 6 control mice and $3 S k n-1 a / i(-/-)$ mice. Shown are the results of a Northern blot hybridization with the indicated probes. $(B)$ Spr-1 protein expression after acute treatment of skin with PMA. After shaving, PMA was applied to the back skin of 2-month-old wild-type (left panel) and $S k n-1 a / i \quad(-/-$; right panel/ mice for $24 \mathrm{hr}$. Tissue sections, fixed with $70 \%$ ethanol and paraffin-embedded, were incubated with antisera specific for Spr-1, followed by indirect immunofluorescence and visualization with Texas red. (C) A schematic model for the function of $S k n-1 a / i$ and Tst- 1 genes in epidermis. The $S k n-1 a / i$ gene appears to inhibit expression of Spr-1 and K14 in keratinocytes of the epidermal wound front. Together, $S k n-1 a / i$ and Tst-1 promote the normal differentiation of epidermal keratinocytes. 
that both factors can bind similar DNA-binding sites, these results suggest that the two factors may have overlapping as well as distinct functions in epidermal keratinocyte regulation. In fact, both factors can stimulate promoters characteristic for differentiating epithelium, such as K10 (Andersen et al. 1993a) and HPVla (Andersen et al. 1997).

The third major octamer-binding factor in epidermal keratinocytes, Oct-1, is present both in undifferentiated and differentiated keratinocytes, consistent with its ubiquitous distribution in other organs (Kambe et al. 1993). The activity of Oct-1 may, however, be regulated in vivo during differentiation (Segil et al. 1991), and this factor may also have overlapping function with that of Skn-1a/i and Tst-1. Oct-2, initially thought to be restricted to B lymphocytes, is expressed highly in undifferentiated epidermal keratinocytes in vitro, a differentiation stage in which expression of Skn-1a and Tst- 1 is very low, suggesting that Oct-2 may have a distinct role from that of Skn-1a and Tst-1. Oct-2, unlike Skn-1a and Tst- 1 , is unable to stimulate the K10 and HPV1A promoters (data not shown).

\section{Promotion of epidermal keratinocyte differentiation in vitro by Skn-1a}

We found that Skn-1a specifically induces expression of the K10 gene when keratinocytes are treated with phorbol ester, suggesting that activation of protein kinase $\mathrm{C}$ is required to observe the $\mathrm{K} 10$-inducing effect of $\mathrm{Skn}-1 \mathrm{a}$. Several other mechanisms could be invoked to explain the combined effect of phorbol ester and Skn-la on epidermal differentiation. The effect may be related to the cell cycle arrest induced by phorbol ester, therefore providing a possible mechanism whereby Skn-1a activity is restricted to post-mitotic suprabasal cells and prevents premature $\mathrm{K} 10$ induction in proliferating basal cells. Induction of the K10 gene by Skn-la is likely to be a direct effect because cotransfection of the K10 promoter with Skn-la into HeLa cells leads to induction of this promoter (Andersen et al. 1993a). Furthermore, the K10 promoter contains several Skn-1a-response elements and binding sites. In this respect Skn-1a may act similar to Pit-1, which directly induces expression of terminal differentiation markers (hormones) in somatotropes, lactotropes, and thyrotropes (Andersen and Rosenfeld 1994). These experiments clearly demonstrate that Skn-la behaves differently from the helix-loop-helix (HLH) protein, MyoD, which induces cell cycle arrest followed by differentiation in muscle cells (Parker et al. 1995). The present findings suggest that Skn-1a exerts effects later in the differentiation program than cell-commitment factors such as $\mathrm{MyoD}$, and that cell cycle arrest may be a prerequisite for Skn-1a actions.

\section{Distinct and overlapping functions for the Skn-la/i and Tst-1 genes in vivo}

In contrast to neuronally expressed POU domain genes /Corcoran et al. 1993; Schonemann et al. 1995; Berming- ham et al. 1996; Erkman et al. 1996; Jaegle et al. 1996; McEvilly et al. 1996), the $S k n-1 a / i$ gene-deleted mouse exhibits no block in epidermal terminal differentiation, as assessed by morphology and the expression of markers of commitment to differentiation ( $\mathrm{Kl}$ and $\mathrm{K} 10$ ) and terminal differentiation (loricrin and filaggrin). However, loricrin expression is modified in $S k n-1 a / i(-/-)$ mice compared with wild-type mice (Fig. 5A). The mechanism underlying this abnormality is unlikely attributable to a decrease in transcription of the loricrin gene because loricrin mRNA levels appear to be normal in the $S k n$ $1 a / i(-/-)$ mice. Rather, it is likely that post-transcriptional regulation or loricrin antigenic determinants are altered in the Skn-1a/i $(-\mid-)$ mice. This abnormality seems to be selective for loricrin because the expression level and pattern of another marker of terminal differentiation, filaggrin, is normal in the $S k n-1 a / i(-/-)$ mouse. When Skn-la is expressed in undifferentiated, phorbol ester-treated keratinocytes in vitro, induction of the commitment-to-differentiation marker $\mathrm{K} 10$ is observed (Fig. 2), yet no abnormality of the expression of such markers is observed in the $S k n-1 a / i$-deleted mice, suggesting that a redundant mechanism may be involved in this initial commitment step.

In contrast with the $S k n-1 a / i|-|-\mid$ mouse, the analysis of Tst-1 $|-|-\mid$ neonatal mice revealed no abnormalities in morphology or expression pattern of differentiation markers. Examination of Tst-1 $(-/-)$ mice that survive 10-14 days after birth showed that in contrast with normal pubs, down-regulation of the differentiation markers $\mathrm{K} 1$ and loricrin, and Skn-la/i is inhibited. However, this abnormality could be secondary to systemic effects of Tst-1, rather than a direct effect of the lack of Tst-1 protein in epidermis, based on the fact that no abnormality in $\mathrm{K} 1$, loricrin, or Skn-1a/i expression is observed in skin from Tst-1 $(-/-)$ mice transplanted onto athymic mice.

The double knockout mice for Skn-1a/i and Tst-1 exhibit epidermal hyperplasia, failure to repress K14 in suprabasal cells, and abnormal Spr-1 gene expression in suprabasal cells. These results, which are consistent with defective control of proliferation/differentiation as keratinocytes leave the basal layer of the epidermis, provide evidence that the $S k n-1 a / i$ and Tst-1 genes carry out redundant functions in skin. The failure to suppress K14 gene expression in suprabasal cells may be related to the previous demonstration that Tst- 1 can exhibit site-independent repression of K14 promoter activity in transient transfection assays (Faus et al. 1994). The requirement of intact $S k n-1 a / i$ and Tst-1 genes for repression of K14 in suprabasal cells is not absolute, because misexpression of K14 is not observed in neonatal mice that are deleted for both genes. This defect may be uncovered by tissue stress such as that seen with wounding and transplantation onto athymic mice. These findings suggest that the Skn-1a/i and Tst-1 genes have overlapping function in regulating differentiation of epidermis. Furthermore, based on their slightly distinct expression patterns, distinct optimal DNA-binding sites (Li et al. 1993) and different transactivation domains, it is not surprising that 
these two proteins can also serve distinct functions in epithelial tissues.

The wounding response provides yet another example in which expression of the $S k n-1 a / i$ gene correlates with expression of differentiation markers in epidermis. Although epithelial cells migrating into a wound exhibit some of the characteristics of undifferentiated proliferating keratinocytes, there is evidence of a distinct differentiation state because they are post-mitotic and express a specific set of keratin genes (K6 and K16) that may facilitate their migratory behavior (Paladini et al. 1996). Our studies of wound healing have demonstrated that in contrast to normal suprabasal cells, the suprabasal cells of the migrating epithelial edge fail to express initial commitment markers $(\mathrm{K} 1)$ as well as terminal differentiation markers (loricrin and filaggrin). Furthermore, these cells express K14 and Spr-1, which are normally restricted to keratinocytes of the basal cell layer and the hair follicle, respectively. Expression of the $S k n-1 a / i$ gene is regulated in a spatial domain that corresponds to the altered keratin gene expression, because the $S \mathrm{kn}-1 \mathrm{a} / \mathrm{i}$ gene is down-regulated in precisely the same region as $\mathrm{K} 1$, loricrin, and filaggrin are down-regulated and K14 and Spr-1 are up-regulated. Furthermore, the observation that during wound healing, expression of K14 and Spr-1 is higher in the $S k n-1 a / i$-deleted mouse than in wildtype controls suggests that the $S k n-1 a / i$ gene acts as a suppressor of these genes in the wound front keratinocytes. Apparently, the $S k n-1 a / i$ gene is expressed at a low level in the wound front, with disruption of the gene leading to enhanced up-regulation of K14 and Spr-1 expression.

In summary, our studies indicate that expression of the $S k n-1 a / i$ gene is linked tightly to differentiation, and that it serves to promote normal epidermal differentiation and to simultaneously inhibit a distinctive keratinocyte differentiation pathway induced by wounding, thereby delineating alternative cell phenotypes. Furthermore, we have demonstrated that the $S k n-1 a / i$ gene has overlapping critical functions with that of the Tst-1 gene in epidermal differentiation.

\section{Materials and methods}

Cultures of human epidermal keratinocytes, nuclear extract preparation, and gel mobility shift assays

Human keratinocytes were isolated from neonatal foreskins, using techniques described previously (Wille et al. 1984; Poumay and Pittelkow 1995). Nuclear extracts from cultured keratinocytes were prepared according to the method described by Schreiber et al. (1989). Nuclear extracts $(0.5$ to $5.0 \mu l)$ were used in the gel mobility shift assay as described previously (Andersen et al. 1993a). The sequence of the DNA-binding sites is as follows: 5'-AAGGGGATCCCTGATTTGCATATTCATGAGAC$3^{\prime}(\mathrm{O}+\mathrm{H}+)^{\prime}, 5^{\prime}$-AAGGGGATCCCTGATGTTCAGATTCATGAGAC-3' $(\mathrm{O}-\mathrm{H}+)^{\prime}$, and 5'-AAGGGGATCCCTGATTTGCATATGAAGGATAC-3' $(\mathrm{O}+\mathrm{H}-)$. In some reactions, $1-2 \mu \mathrm{l}$ of antisera for Skn-1a/i (Andersen et al. 1997), Tst-1 (Bermingham et al. 1996), Oct-1 (Santa Cruz Biotechnology, Inc.), or Oct-2 (Santa Cruz Biotechnology, Inc.) were included.

\section{Adenovirus vector constructions and infections}

Adenovirus type 5 vectors were constructed by cloning fulllength Skn-la and Pit- $1_{\text {W271C }}$ cDNAs downstream of the CMV enhancer/promoter in a shuttle plasmid that was cotransfected with the plasmid pJM17 into 293 cells /Graham and Prevec 1992). Isolated plaques were picked from transfected cells and purified. High-titer viral stocks were made by infecting confluent monolayers of 293 cells, followed by isolation of crude lysates that were used to infect proliferating keratinocytes.

Construction of Skn-1a/i knockout vector and production of mutant mice

Five overlapping genomic clones were obtained by screening an $129 /$ Sv mouse phage library with a ${ }^{32}$ P-labeled Skn-1i cDNA. Intron/exon boundaries around the POU domain were determined by Southern blotting and DNA sequencing. A knockout construct was designed such that $5 \mathrm{~kb}$ of genomic sequence, corresponding to amino acids $140-296$ in the mouse Skn-la cDNA (Yukawa et al. 1993), was replaced with the neomycin gene driven by the phosphoglycerate kinase promoter. The targeting vector also contained $7 \mathrm{~kb}$ of $5^{\prime}$ homologous sequence and $5.5 \mathrm{~kb}$ of $3^{\prime}$ homologous sequence, flanked on both sides by a thymidine kinase gene for negative selection. Mutant ES cell lines were generated as described previously (Schonemann et al. 1995; Bermingham et al. 1996). A panel of four probes, designated A-D in Figure 3, was used to diagnose homologous recombination in ES cells. Mutated ES cells were injected into C57BL/6J blastocysts and mutated mice were produced by crossing agouti offspring with $\mathrm{C} 57 \mathrm{BL} / 6 \mathrm{~J}$ mice as described previously (Schonemann et al. 1995; Bermingham et al. 1996). Experimental analysis was performed on mice that had a mixed 129/Sv-C557BL/6J background. Routine genotype analysis of the $S k n-1 a / i$ gene was performed using PCR with the following primers: 5'-GACTGTGTGGTAGGCTTTAGGATGGT-3' (S1A); 5'-GGCTGAAGAGGAGAAATGATCCTATC-3' (S1B). Genotype analysis of the Tst-1 gene was performed as described previously (Bermingham et al. 1996).

\section{Histology, immunohistochemistry, and in situ hybridization}

Back skin and other tissues were fixed in $10 \%$ buffered formalin, embedded in paraffin, sectioned at 5 to $10 \mu \mathrm{m}$, mounted on glass slides and stained with hematoxylin/eosin for morphological analysis. In wounding experiments, wound cross-sections were analyzed microscopically for the number of closed interstices and the mean length and thickness of the migrating tongues in each sample were recorded. For immunohistochemistry, tissues were either fresh frozen in OCT compound or more commonly fixed in $70 \%$ ethanol, followed by embedding in paraffin as described previously (Werner et al. 1993). The following antisera were used: Skn-1a/i (Andersen et al. 1997), Tst-1 (Bermingham et al. 1996), K10 (Dako Corporation), K1 and K10 (Roop et al. 1984), K14 (Roop et al. 1985), loricrin (Mehrel et al. 1990), filaggrin (Rothnagel et al. 1987), SPR1 (Kartasova et al. 1996), and PCNA (Coulter corporation). In most cases we used a biotinylated goat anti-rabbit IgG secondary antibody (Kirkegaard \& Perry, Gaithersburg, MD) and detection with streptavidin-Texas red. In situ hybridization studies were done as described previously (Andersen et al. 1993a) with the following probes: full-length mouse Skn-1a, 0.7-kb Tst-1 probe described previously (Bermingham et al. 1996), loricrin, K14, K1, and K10 probes described previously (Mehrel et al. 1990), filaggrin (Rothnagel et al. 1987), and SPR1 (Kartasova et al. 1996). 
$\beta$-Galactosidase staining was performed as described previously (Bermingham et al. 1996).

RNA analysis

Isolation of RNA, Northern blots and RNase protection assays were performed as described previously (Andersen et al. 1993b).

\section{Transplants of neonatal skin and wounding studies}

Animal experiments were performed with approval of the University of California, San Diego, Animal Research Committee, and in accordance with guidelines of the NIH. The skin from newborn mice was isolated and placed in tissue culture media at $4^{\circ} \mathrm{C}$. A $2 \times 2-\mathrm{cm}$ full-thickness skin section was excised from 6-8-week-old athymic mice (CD-1 nu/nu) sparing the panniculus carnosus and replaced by the newborn mouse skin within 2-24 hr of harvesting. The graft was sutured with 6-0 silk and covered with dressing of Xeroform (Sherwood Medical, St. Louis, $\mathrm{MN}$ ) and Band-Aids.

Wounding experiments, using the meshed skin graft technique were performed in a slightly modified form from methods described previously (Hansbrough et al. 1992). A $2 \times 2-\mathrm{cm}$ full thickness skin section was excised from the back, sparing the panniculus carnosus, under sterile conditions. Subsequently, the excised skin pad was meshed 3:1 with a Zimmer Meshgraft II (Zimmer, Warsaw, IN), placed back on the wound of the same mouse (with extra tissue removed) and sutured to the edges of the wound with 6-0 silk. Wounds were covered with Xeroform (Sherwood Medical, St. Louis, MO) and cotton gauze. In some experiments we used simple incisional wounding technique, slightly modified from that described by Romer et al. (1996). Animals were sacrificed by cervical dislocation at different days after wounding and $2 \mathrm{~mm}$ of tissue surrounding the wound isolated for RNA preparation or histology, including immunofluorescence and in situ hybridization.

\section{Acknowledgments}

We thank Mirir Seiberg for helpful advice; Eirikur Steingrimsson, Richard V. Pearse II, and Wei Zhang for reading the manuscript; Mary Ayers for help in maintaining mice and Peggy Myer for preparing figures. This work was supported by grants from the NIH (to M.R.P. and M.G.R.), by an American Cancer Society Institutional Research Grant (to B.A.), by a J \& J Focus Award (to M.G.R.), and by a grant from the Mayo Foundation (to M.R.P.). B.A. is supported by a Clinical Investigator Award (DK02411), J.R.B. is supported by a postdoctoral fellowship from the U.S. Army Breast Cancer Initiative, M.G.R. is an investigator with the Howard Hughes Medical Institute.

The publication costs of this article were defrayed in part by payment of page charges. This article must therefore be hereby marked "advertisement" in accordance with 18 USC section 1734 solely to indicate this fact.

\section{References}

Andersen, B. and M.G. Rosenfeld. 1994. Pit-1 determines cell types during development of the anterior pituitary gland. A model for transcriptional regulation of cell phenotypes in mammalian organogenesis. J. Biol. Chem. 269: 2933529338.

Andersen, B., M.D. Schonemann, S.E. Flynn, R.V.D. Pearse, H. Singh, and M.G. Rosenfeld. 1993a. Skn-1a and Skn-1i: Two functionally distinct Oct-2-related factors expressed in epidermis. Science 260: 78-82.

Andersen, B., M.D. Schonemann, R.V.D. Pearse, K. Jenne, J. Sugarman, and M.G. Rosenfeld. $1993 \mathrm{~b}$. Brn-5 is a divergent POU domain factor highly expressed in layer IV of the neocortex. J. Biol. Chem. 268: 23390-23398.

Andersen, B., A. Hariri, M.R. Pittelkow, and M.G. Rosenfeld. 1997. Characterization of $S k n-1 a / i$ POU domain factors and linkage to papillomavirus gene expression. J. Biol. Chem. 272: 1590-1593.

Bermingham, J.R., Jr., S.S. Scherer, S. O'Connell, E. Arroyo, K.A. Kalla, F.L. Powell, and M.G. Rosenfeld. 1996. Tst-1/Oct-6/ SCIP regulates a unique step in peripheral myelination and is required for normal respiration. Genes \& Dev. 10: 17511762.

Black, K.E. and W.W. Jederberg. 1985. Athymic nude mice and human skin grafting. In Models in Dermatology (ed. H.I. Maibach and M.J. Lowe), pp. 228-239. Karger, Basel, Switzerland.

Cooper, M.L., J.F. Hansbrough, T.J. Foreman, S.A. Sakabu, and J.A. Laxer. 1991. The effect of epidermal growth factor and basic fibroblast growth factor on epithelialization of meshed skin graft interstices. In Clinical and experimental approaches to dermal and epidermal wound repair: Normal and chronic wounds. pp. 429-442. Wiley-Liss, Inc., New York, NY.

Corcoran, L.M., M. Karvelas, G.J. Nossal, Z.S. Ye, T. Jacks, and D. Baltimore. 1993. Oct-2, although not required for early B-cell development, is critical for later B-cell maturation and for postnatal survival. Genes \& Dev. 7: 570-582.

Das, G. and W. Herr. 1993. Enhanced activation of the human histone H2B promoter by an Oct-1 variant generated by alternative splicing. I. Biol. Chem. 268: 25026-25032.

Dlugosz, A.A. and S.H. Yuspa. 1993. Coordinate changes in gene expression which mark the spinous to granular cell transition in epidermis are regulated by protein kinase C. J. Cell. Biol. 120: 217-225.

Dover, R. and N.A. Wright. 1994. Epidermal cell kinetics. In Dermatology in general medicine (ed. T.B. Fitzpatrick, A.Z. Eisen, K. Wolff, I.M. Freedberg, and K.F. Austin), pp. 159171. McGraw-Hill, New York.

Erkman, L., R.J. McEvilly, L. Luo, A.K. Ryan, F. Hooshmand, S.M. O'Connell, E.M. Keithley, D.H. Rapaport, A.F. Ryan, and M.G. Rosenfeld. 1996. Role of transcription factors Brn3.1 and Brn-3.2 in auditory and visual system development. Nature 381: 603-606.

Faus, I., H.J. Hsu, and E. Fuchs. 1994. Oct-6: A regulator of keratinocyte gene expression in stratified squamous epithelia. Mol. Cell. Biol. 14: 3263-3275.

Fischer, D.F., S. Gibbs, P. van De Putte, and C. Backendorf. 1996. Interdependent transcription control elements regulate the expression of the SPRR2A gene during keratinocyte terminal differentiation. Mol. Cell. Biol. 16: 5365-5374.

Fuchs, E. 1993. Epidermal differentiation and keratin gene expression. J. Cell. Sci. (Suppl.) 17: 197-208.

Fuchs, E. and C. Byrne. 1994. The epidermis: rising to the surface. Curr. Opin. Genet. Dev. 4: 725-736.

Goldsborough, A.S., L.E. Healy, N.G. Copeland, D.J. Gilbert, N.A. Jenkins, K.R. Willison, and A. Ashworth. 1993. Cloning, chromosomal localization and expression pattern of the POU domain gene Oct-11. Nucleic Acids Res. 21: 127-134.

Graham, F.L. and L. Prevec. 1992. Adenovirus-based expression vectors and recombinant vaccines. Biotechnology 20: 363390.

Hansbrough, J.F., M.L. Cooper, R. Cohen, R. Spielvogel, G. Greenleaf, R.L. Bartel, and G. Naughton. 1992. Evaluation of 
a biodegradable matrix containing cultured human fibroblasts as a dermal replacement beneath meshed skin grafts on athymic mice. Surgery 111: 438-446.

He, X., R. Gerrero, D.M. Simmons, R.E. Park, C.J. Lin, L.W. Swanson, and M.G. Rosenfeld. 1991. Tst-1, a member of the POU domain gene family, binds the promoter of the gene encoding the cell surface adhesion molecule Po. Mol. Cell. Biol. 11: 1739-1744.

Jaegle, M., W. Mandemakers, L. Broos, R. Zwart, A. Karis, P. Visser, F. Grosveld, and D. Meijer. 1996. The POU factor Oct-6 and Schwann cell differentiation. Science 273: 507510.

Jones, P.H., S. Harper, and F.M. Watt. 1995. Stem cell patterning and fate in human epidermis. Cell 80: 83-93.

Kambe, F., S. Tsukahara, T. Kato, and H. Seo. 1993. The POUdomain protein Oct-1 is widely expressed in adult rat organs. Biochim. Biophys. Acta. 1171: 307-310.

Kartasova, T., N. Darwiche, Y. Kohno, H. Koizumi, S. Osada, N. Huh, U. Lichti, P.M. Steinert, and T. Kuroki. 1996. Sequence and expression patterns of mouse SPR1: Correlation of expression with epithelial function. I. Invest. Dermatol. 106: $294-304$

Li, P., X. He, M.R. Gerrero, M. Mok, A. Aggarwal, and M.G. Rosenfeld. 1993. Spacing and orientation of bipartite DNAbinding motifs as potential functional determinants for POU domain factors. Genes \& Dev. 7: 2483-2496.

McEvilly, R.J., L. Erkman, L. Luo, P.E. Sawchenko, A.F. Ryan, and M.G. Rosenfeld. 1996. Requirement for Brn-3.0 in differentiation and survival of sensory and motor neurons. $\mathrm{Na}$ ture 384: 574-577.

Mehrel, T., D. Hohl, J.A. Rothnagel, M.A. Longley, D. Bundman, C. Cheng, U. Lichti, M.E. Bisher, A.C. Steven, P.M. Steinert et al. 1990. Identification of a major keratinocyte cell envelope protein, loricrin. Cell 61: 1103-1112.

Miadelets, O.D. 1995. Epidermal keratinocyte proliferation, differentiation and apoptosis in rats in postnatal ontogeny. Ontogenez 26: 62-67.

Mittal, V., M.A. Cleary, W. Herr, and N. Hernandez. 1996. The Oct-1 POU-specific domain can stimulate small nuclear RNA gene transcription by stabilizing the basal transcription complex SNAPc. Mol. Cell. Biol. 16: 1955-1965.

Paladini, R.D., K. Takahashi, N.S. Bravo, and P.A. Coulombe. 1996. Onset of re-epithelialization after skin injury correlates with a reorganization of keratin filaments in wound edge keratinocytes: Defining a potential role for keratin 16 . I. Cell. Biol. 132: 381-397.

Parker, S.B., G. Eichele, P. Zhang, A. Rawls, A.T. Sands, A. Bradley, E.N. Olson, J.W. Harper, and S.J. Elledge. 1995. p53independent expression of p21cipl in muscle and other terminally differentiating cells [see Comments]. Science 267: 1024-1027.

Poumay, Y. and M.R. Pittelkow. 1995. Cell density and culture factors regulate keratinocyte commitment to differentiation and expression of suprabasal $\mathrm{Kl} / \mathrm{K} 10$ keratins. J. Invest. Dermatol. 104: 271-276.

Romer, J., T.H. Bugge, C. Pyke, L.R. Lund, M.J. Flick, J. Degen, and K. Dano. 1996. Impaired wound healing in mice with a disrupted plasminogen gene. Nature Med. 2: 287-292.

Roop, D.R., C.K. Cheng, L. Titterington, C.A. Meyers, J.R. Stanley, P.M. Steinert, and S.H. Yuspa. 1984. Synthetic peptides corresponding to keratin subunits elicit highly specific antibodies. I. Biol. Chem. 259: 8037-8040.

Roop, D.R., C.K. Cheng, R. Toftgard, J.R. Stanley, P.M. Steinert, and S.H. Yuspa. 1985. The use of cDNA clones and monospecific antibodies as probes to monitor keratin gene expression. Ann. N.Y. Acad. Sci. 455: 426-435.
Rothnagel, J.A., T. Mehrel, W.W. Idler, D.R. Roop, and P.M. Steinert. 1987. The gene for mouse epidermal filaggrin precursor. Its partial characterization, expression, and sequence of a repeating filaggrin unit. J. Biol. Chem. 262: 1564315648.

Rutberg, S.E., E. Saez, A. Glick, A.A. Dlugosz, B.M. Spiegelman, and S.H. Yuspa. 1996. Differentiation of mouse keratinocytes is accompanied by PKC-dependent changes in AP-1 proteins. Oncogene 13: 167-176.

Schonemann, M.D., A.K. Ryan, R.J. McEvilly, S.M. O'Connell, C.A. Arias, K.A. Kalla, P. Li, P.E. Sawchenko, and M.G. Rosenfeld. 1995. Development and survival of the endocrine hypothalamus and posterior pituitary gland requires the neuronal POU domain factor Brn-2. Genes \& Dev. 9: 31223135.

Schreiber, E., P. Matthias, M.M. Muller, and W. Schaffner. 1989. Rapid detection of octamer binding proteins with "mini-extracts," prepared from a small number of cells. Nucleic Acids Res. 17: 6419 .

Segil, N., S.B. Roberts, and N. Heintz. 1991. Mitotic phosphorylation of the Oct-1 homeodomain and regulation of Oct- 1 DNA binding activity. Science 254: 1814-1816.

Stanwell, C., M.F. Denning, S.E. Rutberg, C. Cheng, S.H. Yuspa, and A.A. Dlugosz. 1996. Staurosporine induces a sequential program of mouse keratinocyte terminal differentiation through activation of PKC isozymes. I. Invest. Dermatol. 106: 482-489.

Stenn, K.S. and R. Malhotra. 1992. Epithelialization. In Wound healing: Biochemical and clinical aspects, (ed. K. Cohen, R.F. Diegelmann, and W.J. Lindblad), pp. 115-127. W.B. Saunders Company, Philadelphia, PA.

Thomas, K.R. and M.R. Capecchi. 1987. Site-directed mutagenesis by gene targeting in mouse embryo-derived stem cells. Cell 51: 503-512.

Watt, F.M. 1989. Terminal differentiation of epidermal keratinocytes. Curr. Opin. Cell. Biol. 1: 1107-1115.

Wegner, M., D.W. Drolet, and M.G. Rosenfeld. 1993. POU-domain proteins: Structure and function of developmental regulators. Curr. Opin. Cell. Biol. 5: 488-498.

Welter, J.F., H. Gali, J.F. Crish, and R.L. Eckert. 1996. Regulation of human involucrin promoter activity by POU domain proteins. J. Biol. Chem. 271: 14727-14733.

Werner, S., W. Weinberg, X. Liao, K.G. Peters, M. Blessing, S.H. Yuspa, R.L. Weiner, and L.T. Williams. 1993. Targeted expression of a dominant-negative FGF receptor mutant in the epidermis of transgenic mice reveals a role of FGF in keratinocyte organization and differentiation. EMBO J. 12: 26352643.

Wille, J.J., Jr., M.R. Pittelkow, G.D. Shipley, and R.E. Scott. 1984. Integrated control of growth and differentiation of normal human prokeratinocytes cultured in serum-free medium: Clonal analyses, growth kinetics, and cell cycle studies. J. Cell. Physiol. 121: 31-44.

Yukawa, K., T. Yasui, A. Yamamoto, H. Shiku, T. Kishimoto, and H. Kikutani. 1993. Epoc-1: A POU-domain gene expressed in murine epidermal basal cells and thymic stromal cells. Gene 133: 163-169.

Yukawa, K., K. Butz, T. Yasui, H. Kikutani, and F. Hoppe-Seyler. 1996. Regulation of human papillomavirus transcription by the differentiation- dependent epithelial factor Epoc-1/skn1a. I. Virol. 70: 10-16. 


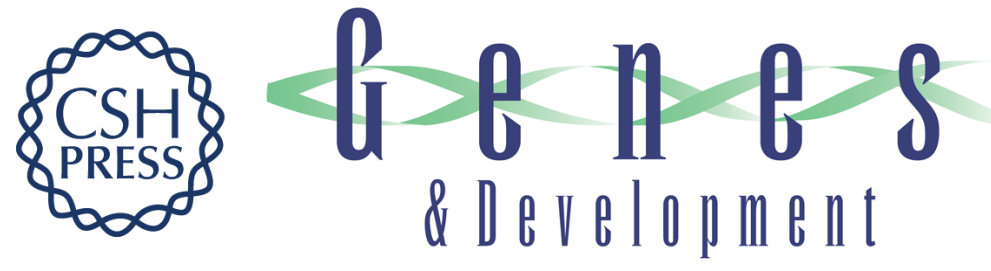

\section{Functions of the POU domain genes Skn-1a/i and Tst-1/Oct-6/SCIP in epidermal differentiation.}

B Andersen, W C Weinberg, O Rennekampff, et al.

Genes Dev. 1997, 11:

Access the most recent version at doi:10.1101/gad.11.14.1873

References This article cites 46 articles, 21 of which can be accessed free at:

http://genesdev.cshlp.org/content/11/14/1873.full.html\#ref-list-1

License

Email Alerting

Service

Receive free email alerts when new articles cite this article - sign up in the box at the top right corner of the article or click here.

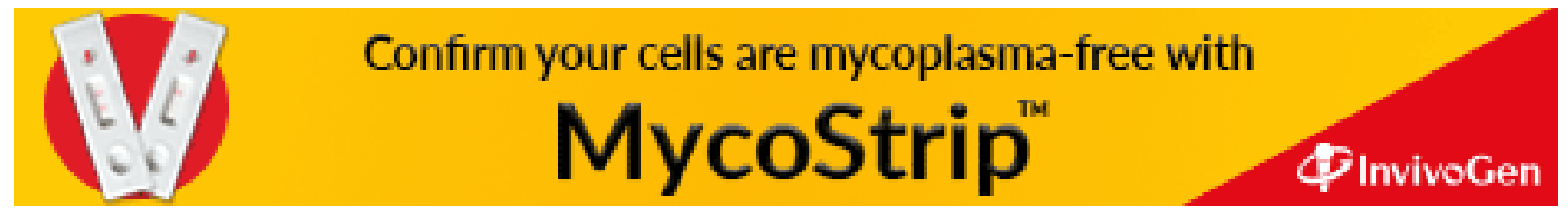

